Corrigendum

\title{
Corrigendum to "Advances in Immunology of Neglected Tropical Diseases: New Control Tools and Prospects for Disease Elimination"
}

\author{
Barbara Castro-Pimentel Figueiredo ${ }^{1}{ }^{1},{ }^{1}$ Carina Silva Pinheiro $\left(\mathbb{D},{ }^{2}\right.$ \\ Fabio Vitarelli Marinho $\left({ }^{3},{ }^{3}\right.$ and Nestor Adrian Guerrero $\mathbb{( i )}^{2}$ \\ ${ }^{1}$ Departamento de Bioquimica e Biofisica, Universidade Federal da Bahia, Salvador, BA, Brazil \\ ${ }^{2}$ Departamento de Biointeracao, Universidade Federal da Bahia, Salvador, BA, Brazil \\ ${ }^{3}$ Departamento de Bioquimica e Imunologia, Universidade Federal de Minas Gerais, Belo Horizonte, MG, Brazil \\ Correspondence should be addressed to Barbara Castro-Pimentel Figueiredo; barbaracpf@ufba.br
}

Received 11 October 2020; Accepted 11 October 2020; Published 24 October 2020

Copyright ( 92020 Barbara Castro-Pimentel Figueiredo et al. This is an open access article distributed under the Creative Commons Attribution License, which permits unrestricted use, distribution, and reproduction in any medium, provided the original work is properly cited.

In the article titled "Advances in Immunology of Neglected Tropical Diseases: New Control Tools and Prospects for Disease Elimination" [1], author Nestor Adrian Guerrero was affiliated to Centro de Biologia Molecular Severo Ochoa, Universidad Autonoma de Madrid, Madrid, Spain, which is incorrect. The correct affiliation for this author is Departamento de Biointeracao, Universidade Federal da Bahia, Salvador, BA, Brazil.

The corrected list of affiliations is shown in the author information above.

\section{References}

[1] B. C.-P. Figueiredo, C. S. Pinheiro, F. V. Marinho, and N. A. Guerrero, "Advances in immunology of neglected tropical diseases: new control tools and prospects for disease elimination," Journal of Immunology Research, vol. 2020, Article ID 9361518, 2 pages, 2020. 